\title{
Sensitivity of Fusarium oxysporum f. sp. niveum to Prothioconazole and Thiophanate-Methyl and Gene Mutation Conferring Resistance to Thiophanate-Methyl
}

\author{
Aparna Petkar, Department of Plant Pathology, University of Georgia, Tifton 31794; David B. Langston, Tidewater Agricultural Research \\ and Extension Center, Virginia Tech, Suffolk 23437; James W. Buck, Department of Plant Pathology, University of Georgia, Griffin 30223; \\ and Katherine L. Stevenson and Pingsheng Ji, Department of Plant Pathology, University of Georgia, Tifton
}

\begin{abstract}
Fusarium wilt, incited by the fungus Fusarium oxysporum f. sp. niveum, is a soilborne disease that affects watermelon production worldwide. Approaches for effective management of Fusarium wilt in watermelon are limited. Studies conducted in recent years indicated that prothioconazole and thiophanate-methyl reduced the disease significantly under field conditions. However, effects of the fungicides on different life stages of $F$. oxysporum f. sp. niveum and potential existence of fungicide resistance in $F$. oxysporum $\mathrm{f}$. sp. niveum populations are unknown. In the present study, effects of prothioconazole and thiophanate-methyl on mycelium growth and spore germination of $F$. oxysporum f. sp. niveum isolates collected in watermelon fields in Georgia were determined. In vitro mycelium growth studies indicated that all 100 isolates evaluated were sensitive to prothioconazole; the effective concentration that suppressed mycelium growth by $50 \%$ ranged from 0.75 to $5.69 \mu \mathrm{g} / \mathrm{ml}$

(averaged $1.62 \mu \mathrm{g} / \mathrm{ml}$ ). In contrast, 33 and $4 \%$ of the isolates were resistant to thiophanate-methyl at 10 and $100 \mu \mathrm{g} / \mathrm{ml}$, respectively. Microconidial germination assays showed that 36 and $64 \%$ of the isolates tested were sensitive or intermediately sensitive to prothioconazole at $100 \mu \mathrm{g} / \mathrm{ml}$ but the fungicide did not inhibit spore germination at $10 \mu \mathrm{g} / \mathrm{ml}$. Sequencing a portion of the $\beta$-tubulin gene of eight isolates resistant or sensitive to thiophanate-methyl indicated that fungicide resistance was associated with a point mutation at nucleotide position 200 , resulting in a substitution of phenylalanine by tyrosine. This is the first report of isolates of $F$. oxysporum resistant to thiophanatemethyl. Results of the research suggest that prothioconazole may be a viable option for management of Fusarium wilt of watermelon whereas thiophanate-methyl should be used judiciously due to the existence of isolates resistant to the fungicide.
\end{abstract}

Fusarium wilt, incited by Fusarium oxysporum f. sp. niveum, is among the most severe diseases in watermelon (Citrullus lanatus var. lanatus) worldwide. In the southeastern United States, the disease has caused increasing damage in watermelon production in recent years. Both seedless and seeded watermelon cultivars can be affected by the disease. In the field, Fusarium wilt may appear early in the watermelon growing season, and a characteristic symptom of the disease is wilting of one or two vines while other vines look healthy. Internal plant tissue discoloration can been seen when lower stems are sectioned. Eventually, plants infected may become completely wilted, especially if young plants get infected. Under conditions favorable for disease development, yield losses of more than $80 \%$ have been reported. This disease is known to have a wide distribution in Asia, the Americas, and other watermelon-growing continents (Egel and Martyn 2013).

Four races of $F$. oxysporum f. sp. niveum have been identified thus far based on their aggressiveness on different watermelon cultivars. Race 0 does not cause significant losses because most watermelon cultivars are resistant to this race. Race 1 is probably the most widely occurring race in the United States and is usually aggressive on seedless watermelon cultivars (Kleczewski and Egel 2011). Race 2 is aggressive on both seeded and seedless watermelons and is known to be established in several watermelon-producing states, including Georgia (Bruton et al. 2008; Kleczewski and Egel 2011). More recently, a new race (race 3) was reported in Maryland, which is more aggressive than the other three races (Zhou et al. 2010).

In the United States, Fusarium wilt has been managed through use of host resistance, such as seeded diploid cultivars of watermelon that are resistant to $F$. oxysporum f. sp. niveum race 1 (Egel and Martyn

Corresponding author: P. Ji; E-mail: pji@uga.edu

Accepted for publication 30 October 2016.

() 2017 The American Phytopathological Society
2013). However, an increase in losses caused by the disease has resulted from increasing production of seedless cultivars that are not resistant to race 1 . Fusarium wilt incidence has also risen due to the prevalence of race 2 of the pathogen, which is more aggressive on diploid cultivars than race 1 . Additionally, an increasing concern to farmers is the emergence of the more aggressive race 3 identified in Maryland (Zhou et al. 2010). Thus far, reliable resistance to all races of $F$. oxysporum $\mathrm{f}$. sp. niveum is not available, especially in commercial triploid cultivars of watermelon.

Other management strategies for $F$. oxysporum $\mathrm{f}$. sp. niveum include grafting and cultural practices. Utilization of cover crops such as vetch (Vicia villosa) and crimson clover (Trifolium incarnatum) prior to planting of watermelon reduced Fusarium wilt in some field studies (Himmelstein et al. 2014; Keinath et al. 2010; Zhou and Everts 2004, 2006). Grafting using nonhost root stocks reduced Fusarium wilt of watermelon; however, the high labor cost incurred with this practice may limit widespread adoption in the United States (Davis et al. 2008; Keinath and Hassell 2014).

Proline (active ingredient [a.i.] prothioconazole; Bayer CropScience, Research Triangle Park, NC) is the only fungicide registered on watermelon in the United States for managing Fusarium wilt. Studies conducted in Georgia indicated that Proline and Topsin (a.i. thiophanate-methyl; United Phosphorus Inc., King of Prussia, PA) reduced the disease significantly under field conditions (Sanders and Langston 2011). More recently, a series of greenhouse and field studies were conducted on watermelon in Maryland, Indiana, Delaware, and Georgia. These studies indicated that thiophanate-methyl and prothioconazole provided the greatest reduction of Fusarium wilt, and prothioconazole in combination with thiophanate-methyl showed a tendency to enhance disease reduction (Everts et al. 2014)

The effects of prothioconazole and thiophanate-methyl on different life stages of $F$. oxysporum $\mathrm{f}$. sp. niveum have not been reported. In addition, it is unknown whether $F$. oxysporum $\mathrm{f}$. sp. niveum populations have developed resistance to the fungicides. Prothioconazole and thiophanate-methyl have different modes of action but they both target single sites (Brent and Hollomon 2007); hence, there is the risk that isolates of $F$. oxysporum f. sp. niveum may develop resistance to one or 
both fungicides. Resistance to thiophanate-methyl by plant pathogens has been reported. Thiophanate-methyl belongs to the methyl benzimidazole carbamate (MBC) fungicide group and acts by binding to tubulin, thereby blocking mitosis (FRAC 2016). The most common mechanism of resistance to MBC fungicides is a change in the amino acid composition of the target molecule, $\beta$-tubulin, often conferred by a single point mutation at specific sites in the gene that encodes the protein (FRAC 2016). Studies on resistance to thiophanate-methyl have focused on pathogens other than Fusarium spp., and resistance has been documented in populations of pathogens such as Botrytis cinerea and Monilinia fructicola (Amiri et al. 2014; Chen et al. 2013; Zhu et al. 2010). Resistance to thiophanate-methyl was due to a glutamic acid to alanine substitution at codon 198 (E198A) in $\beta$-tubulin in M. fructicola (Zhu et al. 2010). Resistance to thiophanate-methyl was also reported due to other mutations in $\beta$-tubulin E198Q or F200Y in M. fructicola (Chen et al. 2013).

The objectives of this research were to (i) determine the effects of prothioconazole and thiophanate-methyl on mycelial growth and microconidial germination of $F$. oxysporum $\mathrm{f}$. sp. niveum isolates infecting watermelon in Georgia and (ii) identify mutations in the $\beta$-tubulin gene of $F$. oxysporum $\mathrm{f}$. sp. niveum isolates that were determined to be thiophanate-methyl resistant in this study. This research would provide information for better utilization of the fungicides in designing effective disease management programs.

\section{Materials and Methods}

F. oxysporum f. sp. niveum isolates. One hundred $F$. oxysporum f. sp. niveum strains isolated from watermelon in commercial fields in Georgia in 2012 and 2013 were used (Fig. 1). Stem sections (3 to $5 \mathrm{~cm}$ ) of symptomatic watermelon plants removed from the hypocotyl region were surface disinfested in sodium hypochlorite $(0.6 \%)$ for $2 \mathrm{~min}$. Plant tissues were rinsed three times in sterile distilled water (SDW) and, after drying on sterile paper towels, tissues were cut into small pieces and placed on semiselective peptone pentachloronitrobenzene agar (Nash and Snyder 1962). After 7 days of incubation in darkness at $25^{\circ} \mathrm{C}$, the plates were examined microscopically and fungal isolates were identified based on morphological criteria for hyphae, microconidia, and macroconidia described previously (Nelson et al. 1983). Putative F. oxysporum f. sp. niveum isolates were grown on potato dextrose agar (PDA) and, after 5 to 7 days of incubation at $25^{\circ} \mathrm{C}$, single-spore cultures were produced from all of the isolates, as described previously (Leslie and Summerell 2006). For long-term storage, a loopful of mycelium of single-spore isolates was placed in 2-ml Microbank vials (Pro-Lab Diagnostics Inc., Round Rock, TX) that are designed for fungal storage and contain treated beads and a cryopreservative solution. The vials were stored at $-80^{\circ} \mathrm{C}$.

Molecular identification. One hundred isolates grown on PDA $\left(25^{\circ} \mathrm{C}, 7\right.$ days) were used for extraction of DNA using a DNeasy Plant Mini kit (Qiagen, Valencia, CA). Polymerase chain reaction (PCR) amplification was conducted using $F$. oxysporum $\mathrm{f}$. sp. niveum-specific primers FON1 and FON2 (Lin et al. 2010). The PCR mixture $(25 \mu \mathrm{l})$ contained PCR buffer $(1 \times), 200 \mu \mathrm{M}$ each dNTP, each primer $(0.5 \mu \mathrm{M})$, Taq DNA polymerase ( $0.5 \mathrm{U})$, and $10 \mathrm{ng}$ of DNA. PCR conditions were as reported by Lin et al. (2010), which included denaturing at $94^{\circ} \mathrm{C}$ for $90 \mathrm{~s} ; 30$ cycles of denaturing at $94^{\circ} \mathrm{C}$ for $30 \mathrm{~s}$, annealing at $62^{\circ} \mathrm{C}$ for $30 \mathrm{~s}$, and polymerization at $72^{\circ} \mathrm{C}$ for $60 \mathrm{~s}$; and a final extension $\left(72^{\circ} \mathrm{C}\right)$ for $10 \mathrm{~min}$. The PCR product was evaluated by electrophoresing in $1.5 \%$ agarose gel containing ethidium bromide $(0.5 \mu \mathrm{g} / \mathrm{ml})$ in $0.5 \times$ Tris-borate-EDTA buffer.

Pathogenicity tests. Watermelon seedlings ('Sugar Baby') were grown in 9-cm-diameter pots containing a sand-peat-vermiculite mixture $(4: 1: 1[\mathrm{vol} / \mathrm{vol} / \mathrm{vol}])$. One hundred isolates were grown on PDA at $25^{\circ} \mathrm{C}$ for 7 days. Five $7-\mathrm{mm}$-diameter agar plugs from the edge of a growing colony were aseptically transferred to a flask $(500 \mathrm{ml})$ with $200 \mathrm{ml}$ of liquid mineral salts medium (Esposito and Fletcher 1961). The liquid culture was incubated for 2 weeks at $23 \pm$ $1{ }^{\circ} \mathrm{C}$ with shaking $(150 \mathrm{rpm})$. Microconidia were harvested by filtering the liquid culture through three layers of sterile cheesecloth. The concentration of the microconidial suspension was determined using a hemocytometer and adjusted to $10^{6}$ spores $/ \mathrm{ml}$ by adding an appropriate amount of SDW. Watermelon seedlings at the first true leaf stage were inoculated by applying $5 \mathrm{ml}$ of conidial suspension to the base of each seedling (Latin and Snell 1986), with 10 plants for each isolate. Ten plants received SDW treatment and served as control. All plants were placed in a greenhouse $\left(28^{\circ} \mathrm{C}\right.$ [day] and $20^{\circ} \mathrm{C}$ [night], 70 to $80 \%$ relative humidity), and Fusarium wilt incidence was recorded at 3 weeks after inoculation. Diseased plants were sampled for isolation and confirmation of the causal agent

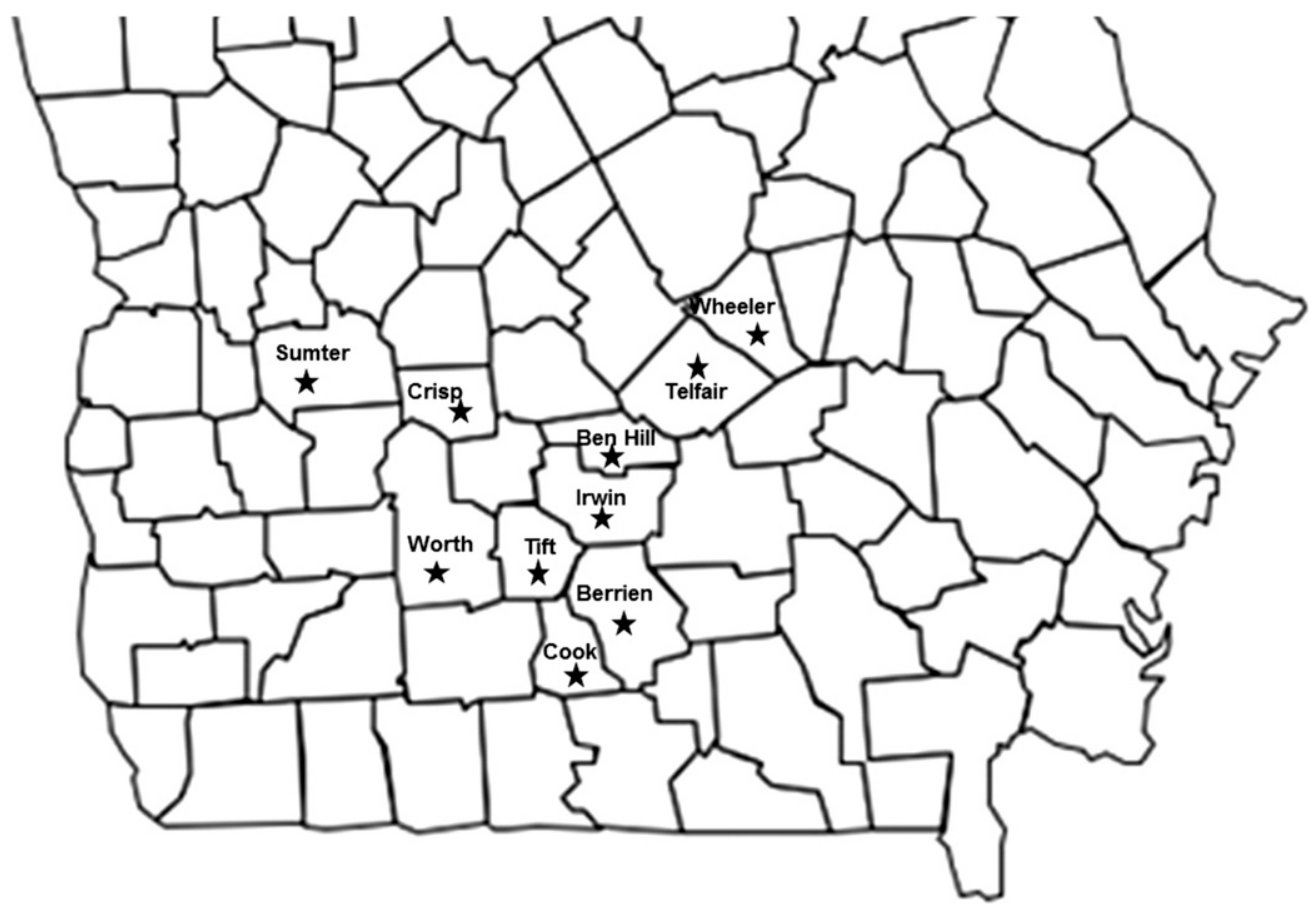

Fig. 1. Locations of watermelon fields in south Georgia for collection of isolates of Fusarium oxysporum f. sp. niveum. Isolates were collected from the counties marked with star symbol. 
using the methods described above. The experiment was conducted twice under similar conditions.

Percentage of fungicide-resistant isolates. A collection of 100 F. oxysporum f. sp. niveum isolates from Georgia was used in the study. Resistance of the isolates to prothioconazole and thiophanate-methyl was determined based on mycelium growth on PDA amended with the fungicides. Technical-grade prothioconazole and thiophanatemethyl (Sigma-Aldrich, St. Louis) were dissolved in acetone to make stock solutions of $10 \mathrm{mg} / \mathrm{ml}$. After autoclaving and cooling to $48^{\circ} \mathrm{C}$, PDA medium was amended using the fungicide stock solutions to final concentrations of 0 (used as control), 10 , and $100 \mu \mathrm{g} / \mathrm{ml}$. The isolates were grown on PDA at $25^{\circ} \mathrm{C}$ for 7 days, and an agar plug $(7 \mathrm{~mm}$ in diameter) was excised from the edge of the colony and placed upside down at the center of the plates amended with the fungicides. Three plates were used for each treatment (fungicide-concentration-isolate). The plates were incubated at $25^{\circ} \mathrm{C}$ for 7 days, and colony diameters on fungicide-amended and nonamended control plates were measured and used to determine resistance to the respective fungicides, as reported previously (Jackson et al. 2012). The percentage of resistant (colony size $>90 \%$ of the control), intermediately sensitive (30 to $90 \%$ of the control), and sensitive ( $<30 \%$ of the control) isolates was calculated. The experiment was conducted twice under similar conditions.

Sensitivity of mycelial growth to prothioconazole. None of the 100 isolates was found to be resistant to prothioconazole at 10 or $100 \mu \mathrm{g} / \mathrm{ml}$; hence, a subset of isolates was selected arbitrarily for determining sensitivity to the fungicide. Eighteen isolates were grown on PDA at $25^{\circ} \mathrm{C}$ in the dark for 7 days. An agar plug was taken as described above and placed on PDA amended with prothioconazole at $0,0.1,0.5,1,3,5$, and $10 \mu \mathrm{g} / \mathrm{ml}$. Three plates were prepared for each concentration and isolate. Colony diameters were measured after incubating at $25^{\circ} \mathrm{C}$ for 7 days, and relative growth (RG) was quantified as the ratio of colony diameter (with diameter of the original plug subtracted) on fungicide-amended medium to that on nonamended medium. The effective concentration that suppressed mycelium growth by $50 \%\left(\mathrm{EC}_{50}\right)$ was calculated for each isolate based on linear regression of probit-transformed relative inhibition $(1-R G)$ on $\log _{10}$-transformed fungicide concentration. The assay was repeated and data from the two experiments were combined. The Shapiro-Wilk test (PROC UNIVARIATE) was used to determine whether frequency distribution of $\mathrm{EC}_{50}$ values followed normality in SAS (version 9.2; SAS Institute Inc., Cary, NC). A paired $t$ test was conducted in order to compare the mean $\log _{10}$-transformed $\mathrm{EC}_{50}$ values among the two experiments.

Effect of prothioconazole on microconidial germination. Fourteen isolates were grown on PDA at $25^{\circ} \mathrm{C}$ in the dark for 7 days. SDW $(5 \mathrm{ml})$ was added to each plate and spores were harvested by gently rubbing the surface of the mycelium with a sterile glass spreader. Spore suspensions were collected in 15-ml sterile centrifuge tubes, and each plate was washed with an additional $5 \mathrm{ml}$ of SDW for spore collection. The concentration of microconidia in each suspension was determined using a hemocytometer and adjusted to approximately $5 \times 10^{3}$ spores $/ \mathrm{ml}$ with SDW. Each suspension $(50 \mu \mathrm{l})$ was spread plated onto water agar amended with prothioconazole at 0 , 10 , and $100 \mu \mathrm{g} / \mathrm{ml}$. Three plates were used for each fungicide concentration and isolate. After incubation $\left(25^{\circ} \mathrm{C}\right)$ for $18 \mathrm{~h}$ in darkness, microconidia were stained with lactophenol cotton blue stain (Smith and MacHardy 1982), and 100 germinated and nongerminated microconidia on each plate were counted. Isolates were classified as resistant (germination rate $>90 \%$ of the control), intermediately sensitive (30 to $90 \%$ of the control), and sensitive ( $<30 \%$ of the control). The experiment was conducted twice, and data from the two experiments were combined after insuring that there was no significant effect of experimenttreatment interactions $(P=0.36)$.

Determining $\boldsymbol{\beta}$-tubulin gene mutation. Eight isolates (four resistant and four sensitive to thiophanate-methyl at $100 \mu \mathrm{g} / \mathrm{ml}$ ) were arbitrarily selected and used to sequence the partial $\beta$-tubulin gene for possible mutations. Total DNA of each isolate was extracted using a DNeasy Plant Mini kit (Qiagen). A partial fragment of the $\beta$-tubulin gene was amplified using the primer sets FU-tubulin2 and FUtubulin3 (Chung et al. 2009). PCR was performed in $25 \mu$ l of reaction

Table 1. Distribution of Fusarium oxysporum f. sp. niveum isolates with different levels of resistance to thiophanate-methyl in different counties in Georgia $^{\mathrm{a}}$

\begin{tabular}{lcccccccc}
\hline & \multicolumn{2}{c}{ Sensitive (\%) } & & \multicolumn{2}{c}{ Intermediate $(\%)$} & & \multicolumn{2}{c}{ Resistant $(\%)$} \\
\cline { 2 - 3 } County & $\mathbf{1 0} \mathbf{~ p p m}$ & $\mathbf{1 0 0} \mathbf{~ p p m}$ & & $\mathbf{1 0} \mathbf{~ p p m}$ & $\mathbf{1 0 0} \mathbf{~ p p m}$ & & $\mathbf{1 0} \mathbf{~ p p m}$ & $\mathbf{1 0 0} \mathbf{~ p p m}$ \\
\hline Ben Hill & 0 & 100 & & 100 & 0 & & 0 & 0 \\
Berrien & 0 & 13.6 & & 52.3 & 77.3 & & 47.7 & 9.1 \\
Cook & 0 & 5 & & 80 & 95 & & 20 & 0 \\
Crisp & 0 & 0 & & 50 & 100 & & 50 & 0 \\
Irwin & 0 & 0 & & 0 & 100 & & 100 & 0 \\
Sumter & 0 & 0 & & 0 & 100 & & 100 & 0 \\
Telfair & 0 & 100 & & 100 & 0 & & 0 & 0 \\
Tift & 0 & 37.5 & & 62.5 & 62.5 & & 37.5 & 0 \\
Wheeler & 0 & 0 & & 100 & 100 & & 0 & 0 \\
Worth & 0 & 0 & & 0 & 100 & & 100 & 0
\end{tabular}

a Sensitivity to the fungicide was determined based on mycelium growth on potato dextrose agar with or without the fungicide. Sensitive, intermediately sensitive, and resistant represent $<30 \%, 30$ to $90 \%$, and $>90 \%$ of growth, respectively, compared with the control.
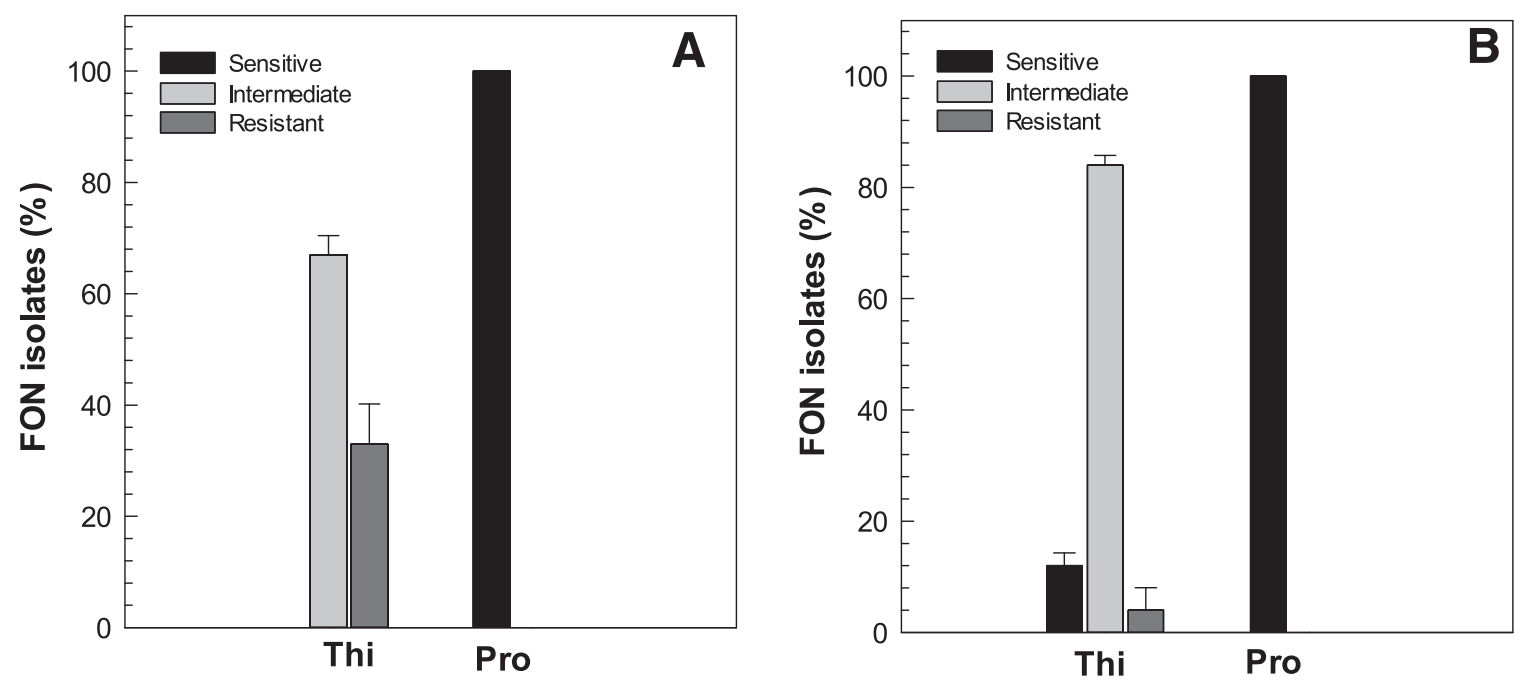

Fig. 2. Percentage of Fusarium oxysporum f. sp. niveum (FON) isolates that were sensitive, intermediately sensitive, or resistant to thiophanate-methyl (Thi) and prothioconazole (Pro) at A, $10 \mu \mathrm{g} / \mathrm{ml}$ and $\mathbf{B}, 100 \mu \mathrm{g} / \mathrm{ml}$ based on mycelial growth of 100 isolates. Error bars indicate standard errors of the means of two repeated experiments. 
mixture containing $1 \mathrm{U}$ of HotStarTaq DNA polymerase (Qiagen), $250 \mu \mathrm{M}$ each dNTP, $0.2 \mu \mathrm{M}$ each primer, and reaction buffer $(2 \mathrm{mM} \mathrm{MgCl} 2)$. The amplification was performed using the protocol reported previously (Chung et al. 2009). A QIAquick PCR purification kit (Qiagen) was used to purify PCR product, and PCR product sequencing was conducted by Eurofins MWG Operon LLC (Louisville, KY). The amino acid sequences were aligned and analyzed using an alignment tool, Clustal Omega (http://www.ebi.ac.uk/Tools/msa/clustalo/).

\section{Results}

Identification of $\boldsymbol{F}$. oxysporum f. sp. niveum isolates. The 100 isolates were identified as $F$. oxysporum $\mathrm{f}$. sp. niveum based on morphological characteristics and PCR analysis using $F$. oxysporum f. sp. niveum-specific primers FON1 and FON2 that produced a 174-bp DNA fragment. In addition, all isolates were tested for pathogenicity by inoculating watermelon seedlings under greenhouse conditions. All isolates caused typical Fusarium wilt symptoms (wilting of stem and leaves) and disease incidence was $100 \% 3$ weeks after inoculation. Seedlings treated with SDW remained asymptomatic.

Percentage of isolates resistant to thiophanate-methyl and prothioconazole. All 100 isolates were sensitive to prothioconazole at 10 or $100 \mu \mathrm{g} / \mathrm{ml}$ (Fig. 2A and B). The percentage of isolates resistant, intermediately sensitive, and sensitive to thiophanate-methyl $(100 \mu \mathrm{g} / \mathrm{ml})$ was 4,84 , and $12 \%$, respectively. With thiophanatemethyl at $10 \mu \mathrm{g} / \mathrm{ml}, 33$ and $67 \%$ of the isolates were resistant and intermediately sensitive, respectively (Fig. 2A; Table 1). Only isolates from Berrien County $(n=4)$ were resistant to thiophanate-methyl at
$100 \mu \mathrm{g} / \mathrm{ml}$ (Table 1). All isolates from Telfair and Ben Hill Counties were sensitive and isolates from Irwin, Crisp, Worth, Sumter, and Wheeler Counties were intermediately sensitive to thiophanatemethyl at $100 \mu \mathrm{g} / \mathrm{ml}$ (Table 1).

Sensitivity of mycelial growth to prothioconazole. $\mathrm{EC}_{50}$ values of prothioconazole for suppressing mycelium growth of the isolates were lognormally distributed. $\mathrm{EC}_{50}$ values were 0.75 to $5.69 \mu \mathrm{g} / \mathrm{ml}$, with a mean of $1.62 \mu \mathrm{g} / \mathrm{ml}$ (Fig. 3). The minimum inhibitory concentrations that inhibited mycelium growth of the isolates completely was 3 to $5 \mu \mathrm{g} / \mathrm{ml}$.

Effects of prothioconazole on microconidial germination. With prothioconazole at $100 \mu \mathrm{g} / \mathrm{ml}, 30$ and $70 \%$ of the 14 tested isolates were sensitive and intermediately sensitive, respectively. Spore germination was not inhibited at $10 \mu \mathrm{g} / \mathrm{ml}$ and germination rates of all isolates on fungicide-amended plates were $>90 \%$ compared with the nonamended control plates.

$\boldsymbol{\beta}$-Tubulin gene mutation. Differences in the amino acid sequence spanning from 190 to 250 were detected between isolates sensitive and resistant to thiophanate-methyl at $100 \mu \mathrm{g} / \mathrm{ml}$. The four isolates sensitive to thiophanate-methyl had phenylalanine at position 200 (TTC) and the four isolates resistant to the fungicide had tyrosine at the position (TAC). The nucleotide changes at amino acid position 200 from TTC (phenylalanine) to TAC (tyrosine) were correlated with resistance of the isolates to the fungicide (Fig. 4).

\section{Discussion}

Fusarium wilt is a troublesome disease in watermelon production in the southeastern United States. Due to limited options for managing the

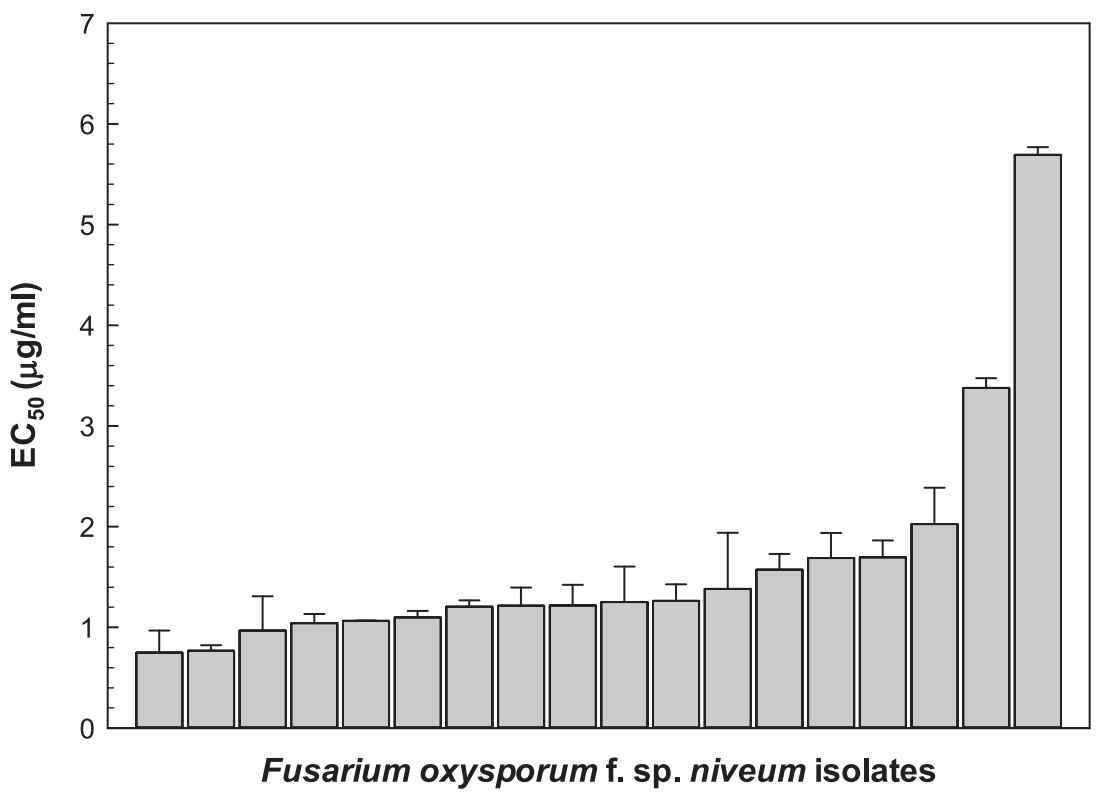

Fig. 3. Concentrations of prothioconazole that were $50 \%$ effective $\left(\mathrm{EC}_{50}\right)$ for inhibiting mycelial growth of Fusarium oxysporum f. sp. niveum isolates. Error bars indicate standard errors of the means of two repeated experiments.

$\begin{array}{lll}\text { Isolate } & \text { Sensitivity } & \text { DNA sequence } \\ & & \\ \text { F12126b } & \text { Sensitive } & 186 \text { GTGCCGGTATGGGTTCTCTGCTCATCTCAAAGATCCGCGAGGAATTTCCCGAC } \\ \text { F12105b } & \text { Sensitive } & \\ \text { F2-39 } & \text { Sensitive } & \\ \text { F2-18 } & \text { Sensitive } & \\ & & \\ \text { F2-50 } & \text { Resistant } & 186 \text { GTGCCGGTATGGGTACTCTGCTCATTTCAAAGATCCGCGAGGAATTTCCCGAC } \\ \text { F2-53 } & \text { Resistant } & \\ \text { F2-31 } & \text { Resistant } & \\ \text { F2-11 } & \text { Resistant } & \end{array}$

Fig. 4. Partial nucleotide sequence of $\beta$-tubulin gene of Fusarium oxysporum f. sp. niveum isolates sensitive or resistant to thiophanate-methyl. Isolates F2-50, F2-53, F2-31, and F2-11are resistant to thiophanate-methyl and isolates F12126b, F12105b, F2-39, and F2-18 are sensitive to the fungicide. The box shows the nucleotide change from TTC to TAC at position 200 that confers resistance to thiophanate-methyl. 
disease, identification of effective fungicides and monitoring development of fungicide resistance in the pathogen populations are highly desirable. Fungicides currently labeled for managing Fusarium wilt on watermelon in the United States are limited; however, field studies conducted in recent years indicated that prothioconazole and thiophanatemethyl were effective in reducing Fusarium wilt on watermelon (Everts et al. 2014; Sanders and Langston 2011). In the present study, prothioconazole was more effective than thiophanate-methyl in suppressing mycelial growth of $F$. oxysporum $\mathrm{f}$. sp. niveum isolates in vitro, and no isolate was resistant to prothioconazole, while isolates resistant to thiophanate-methyl were identified based on in vitro mycelial growth assays. This is the first report documenting existence of $F$. oxysporum f. sp. niveum isolates resistant to thiophanate-methyl in field populations of the pathogen and association of resistance with an amino acid substitution in the $\beta$-tubulin target resulting from a point mutation in the gene.

Thiophanate-methyl has been reported to be effective in reducing diseases caused by Fusarium spp. such as $F$. oxysporum f. sp. vasinfectum in cotton and $F$. oxysporum f. sp. niveum (Doan and Davis 2015; Everts et al. 2014; Sanders and Langston 2011). Information regarding resistance of isolates of Fusarium spp. to this fungicide is limited. In a study by Suga et al. (2011), isolates of $F$. asiaticum resistant to thiophanatemethyl were documented and the resistant isolates had F167Y or F200Y mutations in the $\beta$-tubulin gene. Chung et al. (2009) reported that a few isolates of $F$. oxysporum $\mathrm{f}$. sp. gladioli and $F$. oxysporum f. sp. lilii were resistant to thiophanate-methyl. However, sequencing a partial $\beta$-tubulin gene of the resistant isolates did not identify mutations in either position 198 or 200 , suggesting that other mechanisms might be involved in resistance of the isolates. In the present study, 4 and $33 \%$ of the $F$. oxysporum $\mathrm{f}$. sp. niveum isolates from watermelon were resistant to thiophanate-methyl at 100 and $10 \mu \mathrm{g} / \mathrm{ml}$, respectively, and sequencing the $\beta$-tubulin gene showed that mutation occurred at codon 200 , with tyrosine substituting for phenylalanine in the resistant isolates. No other point mutation in the $\beta$-tubulin gene was found between sensitive and resistant isolates (data not shown).

Prothioconazole is in the demethylation inhibitor fungicide class that affects sterol biosynthesis, thereby disrupting membrane structure (FRAC 2016). It has been shown to be effective in reduction of diseases caused by Fusarium spp. under field conditions, including Fusarium wilt of watermelon (Everts et al. 2014; Sanders and Langston 2011 ) and Fusarium head blight of wheat ( $F$. graminearum) (Freije and Wise 2015). Effects of prothioconazole on different life stages of $F$. oxysporum f. sp. niveum and resistance to this fungicide in populations of Fusarium spp. have not been reported. In a study on F. graminearum in Brazil, prothioconazole inhibited mycelial growth of the pathogen at a concentration of $0.1 \mu \mathrm{g} / \mathrm{ml}$ (Avozani et al. 2014). In the present study, all $100 \mathrm{~F}$. oxysporum $\mathrm{f}$. sp. niveum isolates were sensitive to the compound based on a mycelial growth assay, with an average $\mathrm{EC}_{50}$ value of $1.62 \mu \mathrm{g} / \mathrm{ml}$. Prothioconazole was also active in suppressing microconidial germination at $100 \mu \mathrm{g} / \mathrm{ml}$, with no resistant F. oxysporum f. sp. niveum isolates identified. When tested at a lower concentration $(10 \mu \mathrm{g} / \mathrm{ml})$, microconidial germination of the isolates evaluated was not effectively inhibited. Prothioconazole is suggested to be applied at $200 \mathrm{~g} / \mathrm{ha}$ (label rate) for managing Fusarium wilt on watermelon. This application rate is generally higher than $100 \mu \mathrm{g} / \mathrm{ml}$ and, therefore, should be effective for suppression of mycelial growth and microconidial germination, though it is difficult to accurately estimate concentrations of fungicides on the plants after they are applied.

In summary, prothioconazole was shown to be effective in suppressing mycelial growth of $F$. oxysporum $\mathrm{f}$. sp. niveum isolates in vitro and no isolate was found to be resistant to this fungicide. It was also effective in inhibiting microconidial germination when used at $100 \mu \mathrm{g} / \mathrm{ml}$. Given the limited tools for managing Fusarium wilt of watermelon and the importance of this disease, prothioconazole can be a viable option to be recommended to growers. Thiophanatemethyl was less effective than prothioconazole in inhibiting mycelial growth of the $F$. oxysporum $\mathrm{f}$. sp. niveum isolates, and isolates resistant to thiophanate-methyl were documented based on in vitro assays and analysis of $\beta$-tubulin gene sequences. Hence, thiophanatemethyl should be used judiciously if recommended for managing
Fusarium wilt of watermelon. Further studies can be directed at identification of new effective fungicides, monitoring potential development of resistance to prothioconazole in the pathogen population, and development of integrated disease management programs incorporating prothioconazole with cultural practices such as host plant resistance and effective cover crops. These studies have the promise to reduce the risk of fungicide resistance development and may improve efficacy for managing this important disease.

\section{Acknowledgments}

This research was supported by a United States Department of AgricultureNational Institute of Food and Agriculture Specialty Crop Research Initiative grant that is greatly appreciated.

\section{Literature Cited}

Amiri, A., Zuniga, A. I., Mertely, J., and Peres, N. A. 2014. First report on resistance to pyraclostrobin, thiophanate-methyl, fenhexamid and boscalid in Botrytis cinerea from Eucalyptus seedlings in Florida greenhouses. Plant Dis. 98:851.

Avozani, A., Reis, E. M., and Tonin, R. B. 2014. In vitro sensitivity reduction of Fusarium graminearum to DMI and QoI fungicides. Summa Phytopathol. 40: 358-364.

Brent, K. J., and Hollomon, D. W. 2007. Fungicide resistance in crop pathogens: How can it be managed? FRAC Monogr. No. 1. Fungicide Resistance Action Committee, Brussels.

Bruton, B. D., Fish, W. W., and Langston, D. B. 2008. First report of Fusarium wilt caused by Fusarium oxysporum f. sp. niveum Race 2 in Georgia watermelons. Plant Dis. 92:983.

Chen, F., Liu, X., and Schnabel, G. 2013. Field strains of Monilinia fructicola resistant to both MBC and DMI fungicides isolated from stone fruit orchards in the eastern United States. Plant Dis. 97:1063-1068.

Chung, W. H., Chung, W. C., Ting, P. F., Ru, C. C., Huang, H. C., and Huang, J. W. 2009. Nature of resistance to methyl benzimidazole carbamate fungicides in Fusarium oxysporum f. sp. lilii and F. oxysporum f. sp. gladioli in Taiwan. J. Phytopathol. 157:742-747.

Davis, A. R., Perkins-Veazie, P., Sakata, Y., Lopez-Galarza, S., Maroto, J. V., Lee, S. G., Huh, Y. C., Sun, Z., Miguel, A., King, S. R., Cohen, R., and Lee, J. M. 2008. Cucurbit grafting. Crit. Rev. Plant Sci. 27:50-74.

Doan, H. K., and Davis, R. M. 2015. Efficacy of seed treatments on viability of Fusarium oxysporum f. sp. vasinfectum race 4 in infected cotton seed. Crop Prot. 78:178-184

Egel, D. S., and Martyn, R. D. 2013. Fusarium wilt of watermelon and other cucurbit crops. Online publication. Plant Health Instruct. doi:10.1094/PHI-I2007-0122-01

Esposito, R. G., and Fletcher, A. M. 1961. Relationship of pteridine biosynthesis to action of copper 8-hydroxyquinolate on fungal spores. Arch. Biochem Biophys. 93:369-376.

Everts, K. L., Egel, D. S., Langston, D., and Zhou, X. G. 2014. Chemica management of Fusarium wilt of watermelon. Crop Prot. 66:114-119.

Freije, A. N., and Wise, K. A. 2015. Impact of Fusarium graminearum inoculum availability and fungicide application timing on Fusarium head blight in wheat. Crop Prot. 77:139-147.

FRAC. 2016. FRAC code list 2016: Fungicides sorted by mode of action (including FRAC Code numbering). Online publication. Fungicide Resistance Action Committee. http://www.frac.info/docs/default-source/publications/frac-code-list/fraccode-list-2016.pdf

Himmelstein, J. C., Maul, J. E., and Everts, K. L. 2014. Impact of five cover crop green manures and Actinovate on Fusarium wilt of watermelon. Plant Dis. 98:965-972.

Jackson, K. L., Yin, J., and Ji, P. 2012. Sensitivity of Phytophthora capsici on vegetable crops in Georgia to mandipropamid, dimethomorph, and cyazofamid. Plant Dis. 96:1337-1342.

Keinath, A. P., and Hassell, R. L. 2014. Control of Fusarium wilt of watermelon by grafting onto bottlegourd or interspecific hybrid squash despite colonization of rootstocks by Fusarium. Plant Dis. 98:255-266.

Keinath, A. P., Hassell, R. L., Everts, K. L., and Zhou, X. G. 2010. Cover crops of hybrid common vetch reduce Fusarium wilt of seedless watermelon in the eastern United States. Online publication. Plant Health Prog. doi:10.1094/ PHP-2010-0914-01-RS

Kleczewski, N. M., and Egel, D. S. 2011. A diagnostic guide for Fusarium wilt of watermelon. Online publication. Plant Health Prog. doi:10.1094/PHP-20111129-01-DG

Latin, R. X., and Snell, S. J. 1986. Comparison of methods for inoculation of muskmelon with Fusarium oxysporum f. sp. melonis. Plant Dis. 70:297-300.

Leslie, J. F., and Summerell, B. A., eds. 2006. The Fusarium Laboratory Manual. Blackwell Publishing, Victoria, Australia. doi:10.1002/9780470278376

Lin, Y. H., Chen, K. S., Chang, J. Y., Wan, Y. L., Hsu, C. C., and Huang, J. W. 2010. Development of the molecular methods for rapid detection and differentiation of Fusarium oxysporum and $F$. oxysporum $\mathrm{f}$. sp. niveum in Taiwan. New Biotechnol. 27:409-418.

Nash, S. N., and Snyder, W. C. 1962. Quantitative estimations by plate counts of propagules of the bean rot Fusarium in field soils. J. Phytopathol. 73:458-462. 
Nelson, P. E., Toussoun, T. A., and Marasas, W. F. O. 1983. Fusarium Species: An Illustrated Manual for Identification. Pennsylvania State University Press, University Park.

Sanders, F. H., and Langston, D. B. 2011. Evaluation of selected fungicides for the control of Fusarium wilt and watermelon fruit blotch in Georgia. Plant Dis. Manage. Rep. 5:V156.

Smith, C. A., and MacHardy, W. E. 1982. The significance of tomatine in the host response of susceptible and resistant tomato isolines infected with two races of Fusarium oxysporum f. sp. lycopersici. Phytopathology 72:415-419.

Suga, H., Nakajima, T., Kageyama, K., and Hyakumachi, M. 2011. The genetic profile and molecular diagnosis of thiophanate-methyl resistant strains of Fusarium asiaticum in Japan. Fungal Biol. 115:1244-1250.
Zhou, X. G., and Everts, K. L. 2004. Suppression of Fusarium wilt of watermelon by soil amendment with hairy vetch. Plant Dis. 88:1357-1365.

Zhou, X. G., and Everts, K. L. 2006. Suppression of Fusarium wilt of watermelon enhanced by hairy vetch green manure and partial cultivar resistance. Online publication. Plant Health Prog. doi:10.1094/PHP-2006-0405-01RS

Zhou, X. G., Everts, K. L., and Bruton, B. D. 2010. Race 3, a new and highly virulent race of Fusarium oxysporum f. sp. niveum causing Fusarium wilt in watermelon. Plant Dis. 94:92-98.

Zhu, F. X., Bryson, P. K., Amiri, A., and Schnabel, G. 2010. First report of the $\beta$-tubulin E198A allele for fungicide resistance in Monilinia fructicola from South Carolina. Plant Dis. 94:1511. 